\title{
Library Intelligent Bookshelf Positioning System Research
}

\author{
Jian Lan Liu', a , Li Zhub \\ ${ }^{1}$ College of Mathematics and Computer Science, Jiangxi Science and Technology Normal \\ University, Nanchang, China \\ ${ }^{2}$ College of Mathematics and Computer Science, Jiangxi Science and Technology Normal \\ University, Nanchang, China
}

ajlan0821@163.com, bbailan_1982@sina.com

Keywords: Intelligent bookshelf; RFID; Books tag query; Positioning; Information management

\begin{abstract}
Radio frequency identification technology has characteristics of non-contact, flexible radiation direction, efficient speaking, reading and writing data, large information storage capacity, which has attracted many researchers to introduce library information management technology into the library in order to improve the efficiency of reader's borrowing and the working efficiency of the librarian. This paper, starting from the concept of RFID, analyzes the current intelligent bookshelf system, designs the overall architecture of intelligent bookshelf system based on RFID library, does performance analysis of experimental data, and establishes the main function module of library intelligent bookshelf system, and frame identification system of intelligent bookshelf. Make reasonable system tag data distribution. The system model can fast and accurate locate information books for readers, simplify the process of library, and improve the efficiency of library.

\section{INTRODUCTION}

At present, the technology of radio frequency identification (RFID) is considered to be the most promising technology in the 21 st century, and one of the four core technologies of the Internet of Things [1]. This technology has been widely applied in parking lot parking management, inventory management, supermarket retail portrait identification and other fields, and has become the new hot spot of in-depth study of academia, industry, equipment manufacturing. Global RFID market size will reach $\$ 90$ billion within five years, according to a poll released, and will go hand in hand with the size of mobile phone market [2].

Library is an important place for people to acquire new knowledge. Especially in today's era of knowledge explosion, it has become the important basic survival condition if we want to keep up with the trend of The Times to gain more knowledge from books, inject fresh blood, read and acquire knowledge[3]. The number and categories of library books also refresh the record in time. On the one hand, people can choose a targeted book, on the other hand, large number of books no doubt increases the difficulty of library managers and readers when query and retrieve books; Using radio frequency identification technology in the research of library shelf positioning system can help library information management and help to improve the work efficiency.
\end{abstract}

\section{RFID TECHNOLOGY}

Radio frequency identification technology is based on wireless communication technology's non-contact automatic identification technology, and is a kind of automatic data and information collect technology. Identify target object automatically by rf signal transmission, access to relevant data, and provide background computer processing system for the corresponding data processing; Identification process does not need manual intervention, and data read speed is faster, tracking targets are more accurately, and the overall cost is low. It is adaptable in all kinds of bad environments [4].

RFID system can be divided into two parts: physical part and information technology part. The physical part includes tags, reader and antenna three components; Information technology section contains the host connected to the reader, device drivers, and database and application software. RFID tracking system mainly uses electronic tags for the unique identification of sex object, which is the only UID code label for target recognition. The position space information of the object under test is manifested by communication radio frequency signal strength between readers and electronic tag installed on the objects, and RFID system structure is shown in Figure 1: 


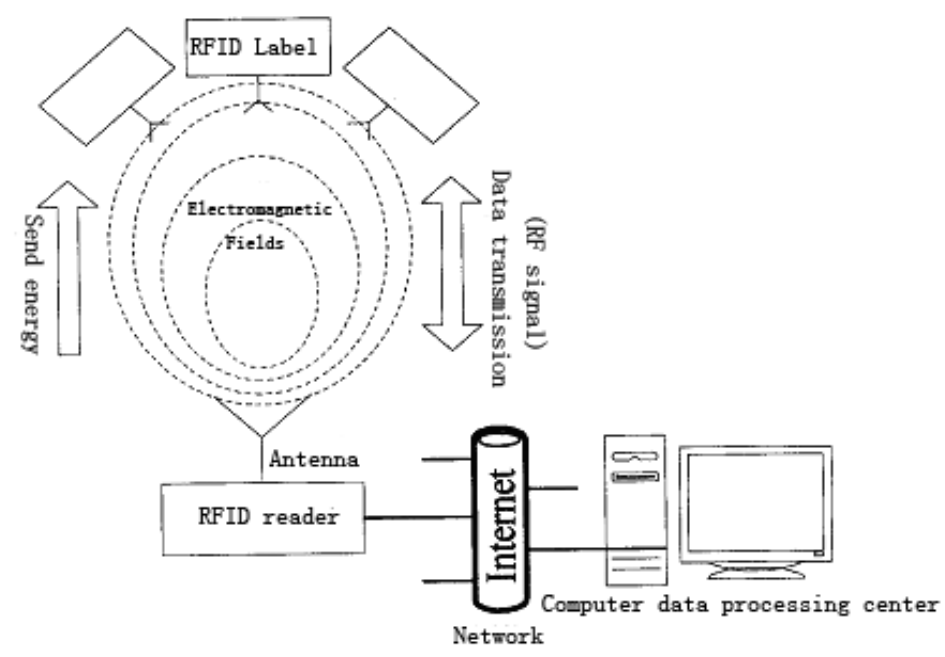

Figure 1 RFID system composition structure

\section{LIBRARY SYSTEM SMART SHELVES DESIGN}

\section{A. Smart shelves system}

Smart shelves system (IBS) is a kind of shelf equipped with RFID readers, RFID tag and RFID transceiver antennas, and reader can at any time detect and locate the current actual location. Through the connection between reader and a computer, real-time process books and location data information; positioning on-shelf books is a set of intelligent, digital and humanized books management system.

Intelligent bookshelf system can detect any moment position of the library collection, namely complete book query location, which implements the intelligent collection book inventory and fault plane statistical functions, which can provide readers with more convenient and quick query service for the readings, improve the efficiency of books borrowed, simplify books borrow process, and enhance the working efficiency of the administrator.

\section{$B$. The overall architecture of library intelligent bookshelf system based on RFID}

Readers need to borrowed books, query operation, such as scheduling, location, search, and librarians need to count the book, on shelf, position management, information management, etc. Smart shelves library management system is mainly composed of system login, book circulation, books management, system management, four parts; Among them, system login includes readers, librarians, login and system administrator login; Book circulation includes books query, book reservation, self-help books borrowing, and self-help books return, and other functions; Books management includes the librarian's lending and return processing operations to readers; Management system consists of a new book catalog information management and information management, reader borrow information management, inventory books, books frame and user information management module, etc.

The application of intelligent bookshelf in library management system is mainly for the convenience of the rapid positioning and finding of the book, which requires the design which has the function of library precise positioning system [5]. Based on RFID, library intelligent bookshelf system is mainly of three parts:

(1) Data collection. Use uhf tags and readers to construct system hardware, paste on every book RFID tags, store memory of initial position information, book information, and install multiple antenna arrays according to certain data format on the label, install multiple ports antenna multiplexer group in bookshelf ontology. The antenna group connects RFID reader through switch control port to facilitate computer control scanning response, and read book tag within the scope.

(2) System database. Readers reads RFID tag information and transfer it via web to the database, and the information includes book information, book shelf information, and the fault plane books' current position coordinates information obtained by RFID localization algorithm, and the data server is mainly about information integration processing and data mining.

(3) Client application. Integrated library management system, query or management interface, 
mainly sends a control command to reader antenna control area, such as intelligent bookshelf system provides book location searching through graphical interface conveniently and intuitively to for readers retrieve books which is shown in Figure 2: Library intelligent bookshelf system overall architecture diagram.

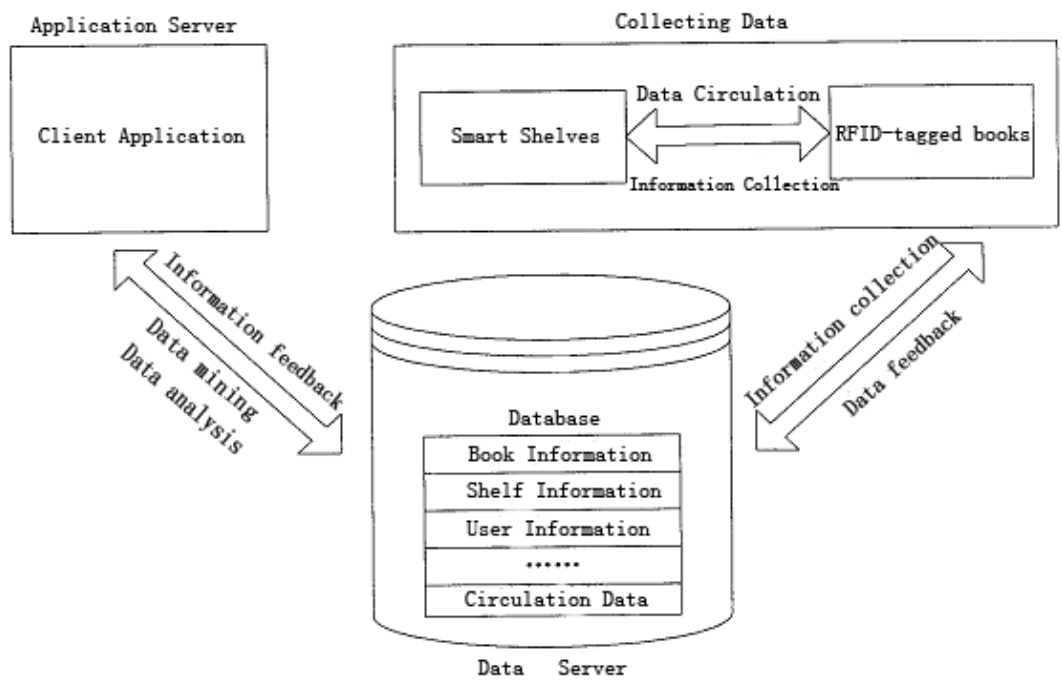

Figure 2 Library intelligent bookshelf system overall architecture diagram

IV. IMPLEMENTATION OF INTELLIGENT BOOKSHELF BASED ON RFID TECHNOLOGY

\section{A. Identification system}

Because smart shelves system uses uhf passive tags, labels cost and volume are low, and label memory is also small, so it is necessary to reasonably plan tag memory; Smart shelves position identification system stipulate the minimum range of location coding format of books, which is not only convenient to book for the initial position information encoding, and is advantageous to wrong book rack location information encoding and decoding; When make library books along the frame, librarians can timely access to the initial position information, which is convenient for book fault return. Smart shelves system consists of three kinds of RFID tags:

(1) Book RFID tag. Identify information on every book. Intelligent bookshelf system needs to paste on each book a RFID tag, and RFID tag store books' unique UID, ISBN number, title, author, publishing house, publishing years, classification, original standard location information, etc.; When the book is wrong on other shelves, the label of the book is a localization algorithm for tags determination.

(2) Minimum cell reference tags. Store tags have actual address every minimum cell, namely the bookshelf coordinates information. Refer label's UID number is position number in system database, which is used to describe intelligent bookshelf reference map to achieve the positioning of fault plane books.

(3) Reader card label. Reader card-label stores information such as name, gender, department, and lending conditions.

B. Intelligent bookshelf system tag data distribution

Bent frame scheme of intelligent bookshelf system will adopt classified shelving system. The deposit location of the book is fixed in the smallest unit. Take "floor number + partition number + bookshelf + bookshelf $\mathrm{AB}$ number + bookshelf layer number + minimum cell number" code structure. As shown in Table 1, it is the position information encoding format of a book.

Table 1 Label location information encoding format

\begin{tabular}{|l|l|l|l|l|l|l|l|l|l|l|}
\hline 0 & 1 & 0 & 3 & 0 & 5 & 1 & 0 & 2 & 0 & 1 \\
\hline Floor & \multicolumn{2}{|c|}{ Partition } & Bookshelf & $\begin{array}{c}\text { Surfac } \\
\mathrm{e}\end{array}$ & $\begin{array}{r}\text { Layer } \\
\text { number }\end{array}$ & Cell number \\
\hline
\end{tabular}

Table 1 tells that book's standard location is on the A surface 2layer 1cell of first floor 3 partitions 5 shelf. Such convenient store coding mode cannot only store books' original standard location information, fix each book's smallest storage scope, improve search efficiency, but facilitate the librarian bent down, entry reference code label location information according to geographical 
position information.

C. Database design

1. Database analysis

Intelligent bookshelf system database is mainly used to store books information, position information, reader card information, etc. The system structure design quality directly affects the efficiency of the system, and reasonable database structure design can also improve the efficiency of data storage, guarantee data consistency and integrity to the greatest extent. The function of library intelligent bookshelf system is make library information management convenient, and it needs large amount of data to extract and obtain reasonable practical information, therefore, reasonable analysis of data structure and database logical relationship makes the whole information management system implementation invoke the data needed quickly and accurately, so it is one of the main indicators of performance for the measure of information system development work [6]. The main data information database has the following aspects:

(1) Reader information. Mainly include reader id number, name, sex, a department of readers, and the user type, contact phone number, etc.

(2) Book information. Mainly include book number (RFID), ISBN number, the index number, name of the book, the author, the translator, press, books category, date of publication, book price and book note.

(3) Book position information. Mainly include floor number, partition, bookcase, bookshelf AB face, bookshelf layer number, minimum cell number.

(4) Borrowing information table. Mainly include lending Numbers, reader card UID, book labels UID, library date, loan period, return book information, overdue and pay.

2. Database logical structure design

In the process of database design, the design of data table needs to combine demand analysis and detailed business function module to design database form [7]. In the form, data objects and information processing object are correlated, design data object according to certain organization form field for description, including field name, field type, field length, and attribute description, etc.

To save and read data is data access. Data stored in the database can be submitted to business logic layer, at the same time save business logic layer processed data to the database, such as reader match with reference tag location information by reading wrong book label signal strength value after business logic layer encapsulation RSS localization algorithm processing and matching, and finally store the current position to establish temporary fault plane books information table in the database, and complete the data processing time and again. The realization of system data access layer is DB class, which contains a variety of methods for database connection, SQL database operation, including perform database query, approach to add or delete and modify data in the database, and perform database stored procedure method, etc.

D. The realization of intelligent bookshelf query positioning system

1. Book query location

The location information query of wrong books is a driven positioning of the response action. There are three main kinds of driving mode orientation: the orientation of reader driver, label drive and reader driver positioning; reader driver positioning requirements for system is minimum with minimum energy consumption, but without reader's wrong books locate request, the position information of the book cannot be timely updated to the current position in a database table, and the book will be always in the wrong frame state; Label drive location is set for each label's wake cycle, rouse themselves for reading, because books in the library are a lot, when multiple tags at the same time launch to own reading request, it will inevitably lead to tag collision. The requirement for collision algorithm is improved; we adopt reader driven orientation, and the positioning method requires a reader in a state of continuous work. Set the work frequency of the reader for every 30 seconds per detect, once book is in wrong position immediately update the calculation results automatically to the database table; there is no waiting time when readers query books, in order to improve query efficiency; Figure 3 is a complete flowchart of reader driver location. 


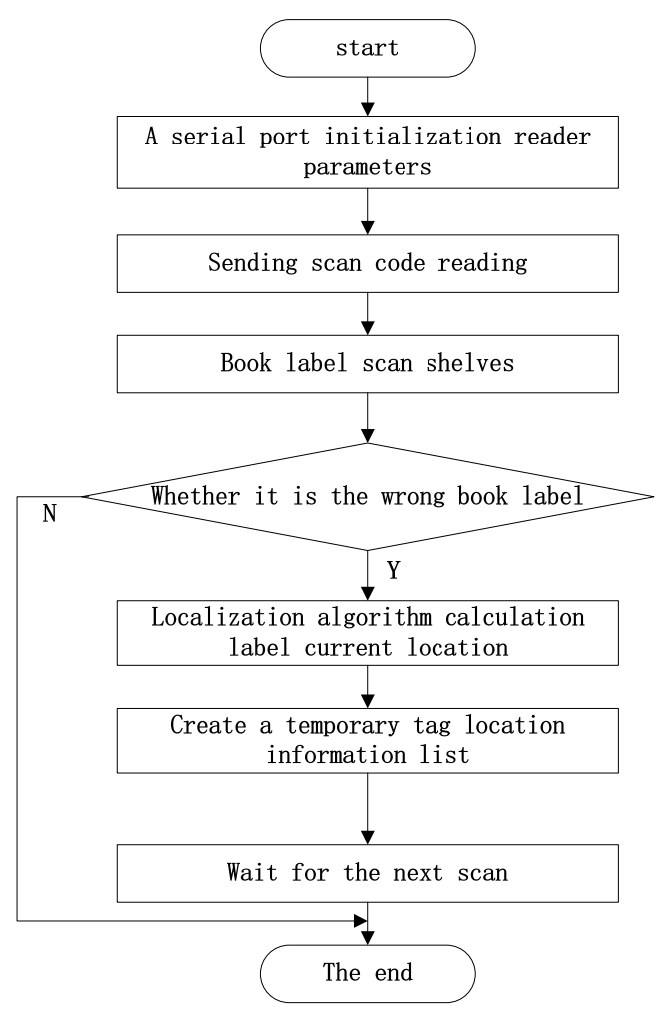

FIG. 3 Flow chart of reader driver location

Described in the Figure, the librarian determines the initial placement of books on a shelf when making suitable frame bent. The books on the shelf need to be matched to readers to determine whether the label is wrong label, and repeat the above process every 30 seconds.

2. The system test

For readers books query, input retrieval way, choose book title, ISBN, index number to retrieve. When there is the reader need to query book retrieval results, check the display position of library, click on the display to display the book collection location.

When librarian makes the book inventory, choose floor, partition number, bookshelf, bookshelf AB face, bookshelf layer number and bookshelf cell number query in location choice, statistical results returned to all books information stored in the place, and provide the wrong book information, mark by colored stripes, and can make statistics about position books total number and wrong number books; readers unfamiliar with the layout of library can choose floor numbers according to its location, and the system will display this shelf layout, and prompt the partition location to help readers quickly find a book according to book collection location information.

\section{CONCLUSION}

With the rapid development of information technology, radio frequency technology application has become an important symbol of intelligence [8]. It is a kind of new information acquisition and processing technology. Using the technology for library intelligent bookshelf system model research and design is to realize the intelligent management of an important content. The current shelf positioning method has higher positioning accuracy, positioning shelf layer precisely to shelf minimum cell, and reduce the complexity of the system and the system cost. It can effectively simplify books borrow process, and improve the automatic identification of books and rapid positioning ability, improve the efficiency of reader's borrowing and administrators working efficiency, and help to realize the intelligent management and improvement of library service level.

\section{REFERENCES}

[1] Yao Yuan. The application of RFID technology in university library research [D]. Shanghai: Shanghai JJiaotong University, 2011.

[2] Liu Hui. Passive RFID positioning system design based on the nearest neighbors label[D]. Tianjin: Tianjin University, 2010.

[3] Wang Dianjun, Lan Yunfeng, Ren Fujun. Indoor mobile robot localization based on active RFID system [J]. Journal of Tsinghua University, 2010, 50 (5) : 673-676. 
[4] Mu Jing. Management information system development tools and application [M]. Beijing: Tsinghua University Press, 2010.

[5] Tan Zhongding. Rfid tracking technology libraries disorderly frame strategy [D]. Journal of Guangxi Academy of Sciences, 2011, 27 (3) : 228-231.

[6] Zhang Yusong, Yang Wenhua. Book management iot general structure analysis and design [J]. Journal of Library Journal, 2012 (12).

[7] Wang Yuanzhe, Mao Luhong, Liu Hui. rfid localization algorithm research and application based on reference tag [J]. Journal of Communications, 2010, 31 (2) : 86-92.

[8] Sun Fa, Liao Wenxian, Pan Pengcheng. The design and implementation of library shelf positioning system [J]. Modern Information Technology, 2008 (12).

[9] Yan Baozhong, Jiang Chen, Yin Weiwei. Indoor location algorithm research based on RFID technology [J]. Computer Simulation, 2010, 27 (2) : 320-324.

[10] Zhao Ying, Fan Xiaoping. Network security data visualization review [J]. Journal of Computer-aided Design and Graphics, 2014 (5).

[11] Jing Xin, Zhang Jing. Iot library automation counting study [J]. Computer Engineering and Application, 2012, 8 (26) : 11-16. 